\title{
CRIATIVIDADE E PRÁTICAS CRIATIVAS EM EDUCAÇÃO MUSICAL: UM ESTUDO DAS PRODUÇÕES RECENTES NOS ANAIS DE CONGRESSOS DA ABEM ${ }^{1}$
}

\author{
Creativity and creative practices in music \\ education: a study of recent productions in the \\ proceedings of Abem's congresses
}

\author{
Creatividad y prácticas creativas en educación musical: \\ un estudio de producciones recientes en actas de \\ conferencias de los congresos de la ABEM
}

\section{Lia ViéGAS MARIZ DE OLIVEIRA PELIZZON \\ Centro Universitário Claretiano \\ liapelizzon@gmail.com}

VIVIANE BEINEKE

Universidade do Estado de Santa Catarina vivibk@gmail.com

Resumo: Esta pesquisa teve o objetivo de investigar como estudos e pesquisas sobre criatividade na educação musical vêm se configurando recentemente nos anais dos congressos nacionais da Associação Brasileira de Educação Musical (Abem). A fundamentação teórica foi construida com base em pesquisas atuais de autores brasileiros e estrangeiros das áreas da educação e da educação musical que focalizam o tema enquanto campo teórico-prático. Quanto à metodologia, foi realizada pesquisa bibliográfica. Foram selecionados 30 textos, sendo utilizado o software MAXQDA 12 para a análise dos dados. As análises tiveram como foco as seguintes dimensões: justificativas que envolvem o desenvolvimento da criatividade, expressões utilizadas pelos autores para tratar do tema, atividades e estratégias metodológicas mais utilizadas e principios teórico-metodológicos que orientam as discussões sobre o tema. As considerações finais destacam a criatividade na educação enquanto campo de estudos que vem crescendo sob diferentes olhares e perspectivas, com destaque às práticas criativas que vêm sendo desenvolvidas em contextos diversos. O crescimento do campo aponta para a crescente valorização e legitimação dos discursos, identidades e processos de significação que emergem das práticas criativas enquanto potencial crítico e transformador no campo da educação musical.

Palavras-chave: Criatividade. Práticas criativas. Pesquisa bibliográfica. Anais de congressos.

Abstract: This research had the objective of investigating how studies and research on creativity in music education have recently been configured in the Proceedings of National Congresses of the Brazilian Music Education Association (ABEM). The theoretical foundation was built based on current research by Brazilian and foreign authors in the areas of education and music education that focus on the theme as a theoreticalpractical field. As for the methodology, a bibliographic research was carried out. We selected 30 texts, using MAXQDA 12 software to analyze the data. The analyzes focused on the following dimensions: justifications that involve the development of creativity, expressions used by the authors to deal with the theme, activities and methodological strategies most used and theoretical and methodological principles that guide the discussions on the theme. The final considerations highlight the creativity in education as a field of studies that has been growing under different perspectives and perspectives, highlighting the creative practices that have been developed in different contexts. The growth of the field points to the increasing appreciation and legitimation of the discourses, identities and processes of signification that emerge from the creative practices as a critical and transformative potential in the field of musical education.

Keywords: Creativity. Creative Practices. Bibliographic Research. Conference Proceedings.

Resumen: Esta investigación se propuso pesquisar cómo estudios e investigaciones sobre la creatividad en la educación musical se han establecido recientemente em actas de conferencias nacionales de la Asociación Brasileña de Educación Musical (ABEM). El marco teórico se calculó sobre la base de las actuales investigaciones de autores brasileños y extranjeros en los ámbitos de la educación y la educación musical que se centra en el tema en lo que se refiere al campo teórico-práctico. En cuanto a la metodología se realizó investigación bibliográfica. Se seleccionaron 30 textos, siendo utilizado el software MAXQDA 12 para el análisis de datos. Los análisis se centraron en los siguientes aspectos: las justificaciones que implican el desarrollo de la creatividad, las expresiones utilizadas por los autores para tratar el tema, las actividades y las estrategias metodológicas más utilizadas y princípios teórico-metodológicos que guian las discusiones sobre el tema. Las observaciones finales ponen de relieve la creatividad en la educación como un campo de estudio que ha ido creciendo bajo diferentes miradas y perspectivas, con énfasis en las prácticas creativas que se están desarrollando en diferentes contextos. El crecimiento de este campo apunta para el creciente reconocimiento y legitimación de los discursos, identidades y procesos de significación que emergen de las prácticas creativas mientras potencial crítico y transformador en el campo de la educación musical.

Palabras clave: Creatividad. Prácticas creativas. Investigación bibliográfica. Actas de conferencias.

${ }^{1} \mathrm{O}$ presente trabalho foi realizado no curso de mestrado do Programa de Pós-Graduação em Música (PPGMUS) da Universidade do Estado de Santa Catarina (Udesc), com apoio da Coordenação de Aperfeiçoamento de Pessoal de Nível Superior - Brasil (Capes) - Código de Financiamento 001. 


\section{INTRODUÇÃO}

A criatividade vem sendo, cada vez mais, foco de discussões em diversos contextos educativos, em diferentes campos do conhecimento. $\mathrm{Na}$ área da educação musical, apresentam-se argumentos que discutem a criatividade enquanto dispositivo para um desenvolvimento imaginativo que incentiva e possibilita reflexões, tomadas de decisões, resoluções de problemas e julgamentos que valorizam o aluno enquanto protagonista de seu próprio processo de aprendizagem.

Pensar sobre criatividade na educação implica considerar diferentes aspectos, envolvendo questões sociais, culturais, psicológicas, antropológicas, históricas e políticas nas mais diversas dimensões da vida. Craft (2010) argumenta que a criatividade vem sendo compreendida como uma demanda social, principalmente no que se refere aos processos de aprendizagem:

É importante perceber como a criatividade é relevante para todos os aspectos da aprendizagem [...]. É relevante na matemática, assim como na arte, é relevante no faz de conta e na resolução de uma disputa no playground, ou na produção de ideias na área de design e tecnologia. É tão relevante nas texturas de tinta na pintura, na produção de massa e areia, quanto é no trabalho que temos que realizar para entender o último jogo de computador. É relevante para a vida [...] (Craft, 2010, p. 124).

Esses argumentos repercutem no âmbito educacional, à medida que compreende-se a importância de que os estudantes tenham a oportunidade de se posicionar diante de situações com autonomia, tomando decisões e construindo suas identidades. Incertezas, complexidades, progressos e mudanças vêm gerando desafios e problemáticas imprevisíveis, requerendo soluções criativas (Alencar, 2007, p.45). Nesse sentido, a educação, de modo geral, deveria acompanhar essas mudanças e desafios da atualidade, inclusive na área da educação musical.

No Brasil, a literatura aponta o crescimento de pesquisas que visam compreender a criatividade e as práticas criativas em educação musical (Beineke, 2009, 2015; Fonterrada, 2015a; Vieira, 2014). Os trabalhos destacam a relevância de pesquisas sobre essa temática, a importância das práticas criativas nos processos de ensino e aprendizagem musical e o incremento dessas práticas em diferentes contextos educacionais. Fonterrada (2015a) observa que professores de música e pesquisadores vêm ampliando estudos acerca da criatividade, mas que ainda são necessárias ações que consolidem essas práticas no País.

Considerando tais argumentos, esta pesquisa teve o objetivo de investigar como estudos e pesquisas sobre criatividade na educação musical vêm se configurando recentemente nos anais dos congressos nacionais da 
Associação Brasileira de Educação Musical (Abem). Para tanto, as publicações selecionadas nesta pesquisa são contextualizadas e analisadas considerando os seguintes objetivos específicos: (1) identificar as expressões que emergem nos textos analisados para discutir criatividade em educação musical; (2) analisar de que maneira a temática está sendo justificada nos contextos de educação musical; (3) discutir as atividades e estratégias metodológicas utilizadas para implementar práticas criativas em educação musical; e (4) compreender os princípios teórico-metodológicos que orientam as discussões sobre o campo nos contextos de educação musical.

É importante destacar que, nesta pesquisa, os termos criatividade e práticas criativas são utilizados de forma distinta para definir os campos teórico-conceituais e da prática educativa. Desse modo, o termo criatividade se refere ao campo de pesquisa, incluindo teorias, conceitos e definições. Já a expressão práticas criativas contempla os dispositivos utilizados visando o desenvolvimento da criatividade, isto é, os procedimentos e os princípios que possibilitam que a criatividade emerja, tais como as atividades e estratégias metodológicas que visam o fazer musical criativo.

\section{CRIATIVIDADE E EDUCAÇÃO MUSICAL}

Craft (2005) enfatiza que diferentes abordagens consideram os contextos onde ocorre a criatividade, qual seu impacto e/ou qual o tipo de resultado. Por mais que as pesquisas forneçam diferentes olhares para o campo, existe um consenso que reconhece que a criatividade envolve a "geração de novas ideias" (Craft, 2005, p. 27). Buscando conceituar criatividade, Tafuri (2006, p. 135) explica que esta é considerada como o ato e o processo de se gerar algo novo, sendo a novidade e a originalidade reconhecidas enquanto os aspectos mais importantes do produto criativo. Sobre isso, Czikszentmihalyi (1997) explica a criatividade como um processo no qual diferentes áreas do conhecimento são transformadas culturalmente.

$\mathrm{Na}$ área da educação, Craft $(2005,2010)$ argumenta que proporcionar a expressão criativa desde os primeiros anos do aprendizado auxilia os alunos a enfrentarem os desafios e a resolverem os problemas que enfrentarão no decorrer de toda a vida de forma criativa. Além disso, durante o desenvolvimento das crianças no período escolar, a criatividade proporciona satisfação e prazer quando atrelada ao processo de aprendizagem.

Pesquisas consideram a necessidade de a criatividade permear os processos de ensino e aprendizagem na educação musical (Beineke, 2009; 2015; Burnard, 2000, 2006; Tafuri, 2006). Além disso, destacam a importância de se refletir sobre as práticas criativas como um modo de desenvolvimento do processo educativo. Esta reflexão envolve a avaliação dos objetivos de aprendizagem, o diálogo com os sujeitos que compartilham do mesmo contexto - como estudantes, outros professores e a comunidade -, a mediação e adaptação de conhecimentos de fora do contexto educativo para 
o espaço de ensino e aprendizagem e o compromisso de monitoramento da prática de modo contínuo (Craft; Paige-Smith, 2010, p. 38). Esse processo reflexivo deve envolver, também, a documentação das práticas de modo a avaliar e analisar não apenas o desenvolvimento dos alunos, mas também todo o sistema educacional, considerando o contexto em que a prática criativa ocorre.

Em relação às pesquisas que focalizam o tema, Burnard (2012) explica que, dependendo da proximidade dos pesquisadores com outras áreas, como a Psicologia, Sociologia ou História, suas pesquisas partem de diferentes questionamentos.

Como o tema da pesquisa em si é uma questão de debate entre as orientações intelectuais concorrentes, as pesquisas diferem entre si nas maneiras pelas quais veem a sociedade, os atores sociais e os processos. Somado a essa falta de consenso, está o problema de que a criatividade musical é concebida de maneira diferente e construida diferentemente em diferentes práticas históricas (Burnard, 20012, p. 10-11, tradução nossa, grifos da autora).

Segundo Kraemer (2000, p. 66), o conhecimento pedagógico-musical é complexo, à medida que se constrói no cruzamento das ciências humanas, em áreas como a Antropologia, a Filosofia, a História e a Pedagogia, orientadas pela cultura musical e ideias estético-musicais. Nessa perspectiva, nesta pesquisa os trabalhos sobre criatividade na educação musical são entendidos enquanto um campo em construção nas interfaces entre estudos e pesquisas nas áreas da educação, da educação musical e da criatividade, valorizando também suas conexões com outras áreas das ciências humanas.

É relevante observar como os trabalhos no Brasil vêm dialogando e se articulando na configuração do campo da criatividade na educação musical. Pesquisas bibliográficas podem contribuir para a compreensão de como os estudos sobre criatividade estão sendo utilizados pelos pesquisadores e profissionais da área, permitindo a elaboração de um quadro conceitual mais amplo (Lima; Mioto; 2007). Nessa direção, publicações da educação musical podem fornecer dados importantes para o estudo sobre como a área vem se constituindo.

Os congressos nacionais da Abem têm como público-alvo estudantes, professores, pesquisadores, além do público interessado na área da educação musical, tendo como objetivo:

[...] possibilitar aos professores de música participantes a troca de experiências múltiplas, a divulgação de seus trabalhos e experiências, a estruturação de propostas efetivas de educação e pesquisa, e a redefinição de ações e o incentivo à capacitação profissional e à produção intelectual no campo da educação musical (Abem, s.d.). 
Percebe-se que a finalidade dos eventos está relacionada com as experiências práticas da profissão do professor de música, sendo os anais de eventos a forma de registro dessas discussões. É importante diferenciar o escopo e os objetivos das publicações da Revista da Abem daquelas dos anais dos congressos, pois, enquanto o enfoque da revista é a divulgação de conhecimentos consolidados na área por meio de pesquisas de cunho científico, teórico ou histórico, ${ }^{2}$ os anais apresentam processos de pesquisa que podem refletir como o campo vem desenvolvendo seus trabalhos através de olhares para suas práticas educativas.

Ao revisar as publicações da Revista da Abem dos últimos 10 anos (20082018), foram encontrados dez artigos que focalizam a criatividade em processos de ensino e aprendizagem de música. É possivel verificar que os textos possuem diferentes enfoques, referenciais teórico-metodológicos e, consequentemente, contribuições distintas para a área. Dentre as principais discussões apresentadas nos artigos revisados, destacam-se os processos de criação e expressão humana (Brito, 2015, 2010), a aprendizagem criativa e ensino criativo em processos de composição musical de crianças (Beineke, 2008, 2011, 2015; Visnadi; Beineke, 2016), os fundamentos da composição musical na abordagem de Schoenberg (Pereira Jr.; Hartmann, 2017), os processos heurísticos na prática criativa (Nazario; Mannis, 2014), a pesquisa sobre cognição em processos de criação musical (Webster, 2016) e a avaliação de processos criativo-musicais (Frega, 2010).

As pesquisas citadas evidenciam os processos de significação atribuídos à experiência musical criativa. Os trabalhos de Brito $(2015,2010)$, Nazario e Mannis (2014), Visnadi e Beineke (2016) e Beineke (2015, 2011, 2008) concordam que as atividades criativas desenvolvidas em ambientes coletivos e colaborativos exercem papel fundamental no desenvolvimento da imaginação, valorizando as experiências musicais dos alunos e possibilitando a transformação de suas ideias de música. ${ }^{3}$ Para além dos conhecimentos musicais, argumentam que a criatividade na educação musical exerce papel fundamental no desenvolvimento humano e nas afirmações de identidades individuais e coletivas, conforme explica Brito:

Estimulando a criação, a ampliação de possibilidades para fazer música, integrando fazer e pensar, em planos que, inclusive, buscam transformar as relações entre toda a comunidade envolvida, torna-se possivel fazer da experiência musical nos territórios da educação, um jogo de transformação humana essencial (Brito, 2015, p. 22).

\footnotetext{
2 Informações retiradas do site da Revista da Abem:

http://www.abemeducacaomusical.com.br/revistas/revistaabem/index.php/revistaabem/about/editorialPolici es\#focusAndScope. Acesso em: 10 maio 2019.

${ }^{3}$ Conceito fundamentado em Brito (2007) que se refere à mobilidade do pensamento musical no decorrer do tempo e dos espaços em que acontece em relação ao pensamento musical de crianças, utilizado nos trabalhos de Brito (2015, 2010), Visnadi e Beineke (2016) e Beineke $(2015,2011,2008)$.
} 
Considerando as diversas perspectivas teórico-metodológicas que envolvem o campo da criatividade e as diferentes práticas relacionadas a ele, esta pesquisa parte do seguinte questionamento: de que maneira estudos e pesquisas sobre criatividade na educação musical vêm se configurando nos anais dos congressos nacionais recentes da Abem? Para tal, foram traçados os caminhos metodológicos da pesquisa, descritos a seguir.

\title{
CAminhos metodolóGicos
}

Esta pesquisa utilizou como método a pesquisa bibliográfica, que consiste em uma abordagem sistemática, explícita e reproduzivel na qual se busca a identificação, a síntese e a avaliação do corpo textual existente em trabalhos produzidos (Gray, 2009, p. 87). Este método, segundo Marconi e Lakatos (2003, p. 183), visa a análise de um tema a partir de uma nova abordagem ou enfoque. Nessa pesquisa, o fenômeno estudado consiste no campo da criatividade na educação musical por meio de estudos dos trabalhos publicados nos anais dos congressos nacionais da Abem ${ }^{4}$ dos anos de 2015 e 2017. Como critérios para a seleção dessa fonte de dados, foram consideradas: a possibilidade de estudar um campo em construção, visto que os anais de congressos tendem a apresentar trabalhos não consolidados, apontando tendências ou a emergência de perspectivas teóricas; o fato de que os anais incluem pesquisas em andamento e relatos de experiência que nos permitem analisar e compreender também como as práticas criativas estão se configurando nos contextos educativos, e, por fim, a representatividade e a importância da Abem. Sobre este último aspecto, Del Ben (2007) argumenta:

\begin{abstract}
A Abem tem sido a grande responsável pela divulgação e circulação da produção científica brasileira em educação musical, tanto por meio dos encontros nacional e regionais onde pesquisadores, formadores, professores e futuros professores de diversos lugares do país podem partilhar conhecimentos e experiências de ensino e pesquisa - quanto por suas publicações (Del Ben, 2007, p. 57-58).
\end{abstract}

O início do processo de seleção dos dados consistiu em um levantamento dos trabalhos publicados em 2015 e 2017. Optou-se por restringir aos dois últimos congressos nacionais por considerar a importância de uma análise aprofundada dos princípios de criatividade apresentados nos trabalhos, e não na busca de um parâmetro temporal. Ainda, é importante salientar que este trabalho não visa estabelecer o estado da arte do campo da criatividade na

\footnotetext{
${ }^{4}$ Conforme consta em seu site: "A ABEM (Associação Brasileira de Educação Musical) é uma entidade nacional, sem fins lucrativos, fundada em 1991, com o intuito de congregar profissionais e de organizar, sistematizar $e$ sedimentar o pensamento crítico, a pesquisa e a atuação na área da educação musical. Ao longo dessa trajetória, a Associação vem promovendo encontros, debates e a troca de experiências entre pesquisadores, professores e estudantes da educação musical dos diversos níveis e contextos de ensino. A ABEM está vinculada à Associação Nacional de Pesquisa e Pós-Graduação em Música (ANPPOM) e é membro da ISME (International Society for Music Education)." Disponível em: http://abemeducacaomusical.com.br/abem.asp. Acesso em: 25 nov. 2018.
} 
educação musical, mas, sim, investigar as perspectivas teórico-metodológicas que emergem em trabalhos sobre criatividade em educação musical.

Para tal, buscou-se nos títulos, resumos e palavras-chave, expressões relacionadas à criatividade em educação musical, como práticas criativas, criatividade, criação, composição, improvisação, arranjo e paisagem sonora. Os 42 trabalhos que incluiam essas expressões foram lidos integralmente, sendo selecionados 17 trabalhos (6,2\%) nos anais de 2015 e 13 trabalhos $(6,9 \%)$ nos anais de 2017 , totalizando 30 textos.

Os textos selecionados foram organizados e importados para o software de análise qualitativa de dados MAXQDA 12. Optou-se por utilizar essa ferramenta pois, de acordo com Gibbs (2009, p. 136), o uso de softwares de análise de dados auxilia no gerenciamento de dados de modo mais eficiente, sistemático e coerente, proporcionando maior rigor metodológico.

Após importar dos textos para o software, iniciou-se o processo de análise por meio da leitura e da codificação dos textos, sendo possível organizar os arquivos e tratar os dados em uma só tela, sem a necessidade de lidar com diversas impressões em papel ou com vários arquivos na tela do computador. Conforme afirma Charmaz (2009, p. 69), "codificar significa nomear os segmentos de dados com uma classificação que, simultaneamente, categoriza, resume e representa cada parte dos dados". Esse processo é realizado pelo pesquisador, sendo que o software apenas auxilia este trabalho por meio de suas ferramentas de organização dos dados codificados.

O processo de categorização se deu de forma indutiva, ou seja, as categorias de análise foram emergindo dos textos através das leituras e codificações. Destas codificações emergiram as quatro principais dimensões da análise que contribuíram no delineamento dos objetivos específicos da pesquisa: (1) expressões que emergem nos textos; (2) justificativas; (3) atividades e estratégias metodológicas; e (4) principios teórico-metodológicos. A seguir, apresentamos uma contextualização dos trabalhos analisados e os resultados da pesquisa, estruturados em conformidade com as categorias citadas acima.

\section{DIMENSÕES DA CRIATIVIDADE E DAS PRÁTICAS MUSICAIS CRIATIVAS}

\section{Contextualização dos trabalhos}

Os trabalhos apresentados nos congressos nacionais da Abem, segundo as chamadas de trabalho da Associação, podem consistir em (1) projetos de pesquisa ou pesquisa em andamento, (2) pesquisa concluída ou (3) relato de experiência. Desse modo, os 30 trabalhos selecionados para esta pesquisa foram classificados de acordo com as modalidades de trabalhos propostas na chamada de trabalhos do último Congresso Nacional da Abem, em 2017, 
totalizando 6 projetos de pesquisa ou pesquisa em andamento, 6 pesquisas concluidas e 18 relatos de experiência.

Além das modalidades, a Abem organiza os Grupos de Trabalho (GT) em quatro eixos temáticos: 1) dimensões investigativas, epistemológicas e históricas da educação musical; 2) educação musical em contextos formais de ensino; 3) espaços diversos e temáticas emergentes em educação musical; e 4) formação do educador musical. Ao analisar os Grupos de Trabalhos (GT) em que os textos se enquadram, notou-se uma predominância de trabalhos apresentados no eixo temático "Educação musical em contextos formais de ensino", mais especificamente no GT que focaliza o ensino e aprendizagem de música nas escolas de educação básica. Sobre isso, vale destacar que a maior parte dos trabalhos deste GT foram desenvolvidos por autores que têm vínculo com instituições de ensino superior, revelando uma atenção dos profissionais atuantes no ensino superior com a escola básica.

Identificou-se também uma predominância de trabalhos desenvolvidos nas regiões Sul e Nordeste, destacando-se as publicações vinculadas à Universidade Federal da Bahia (UFBA) e à Universidade do Estado de Santa Catarina (Udesc), com três trabalhos cada uma. É importante destacar que o Congresso Nacional da Abem de 2015 foi realizado em Natal/RN, o que provavelmente facilitou a participação de pesquisadores da região Nordeste. No entanto, o Congresso Nacional da Abem do ano de 2017 foi realizado em Manaus/AM, região Norte do País e a região com menos textos selecionados para a pesquisa. O gráfico a seguir (Figura 1) apresenta os números de trabalhos e instituições em relação às regiões do Brasil, que permite observar que, mesmo com a distância geográfica em relação aos locais dos eventos, sobressaem os trabalhos provenientes da região Sul do Brasil.

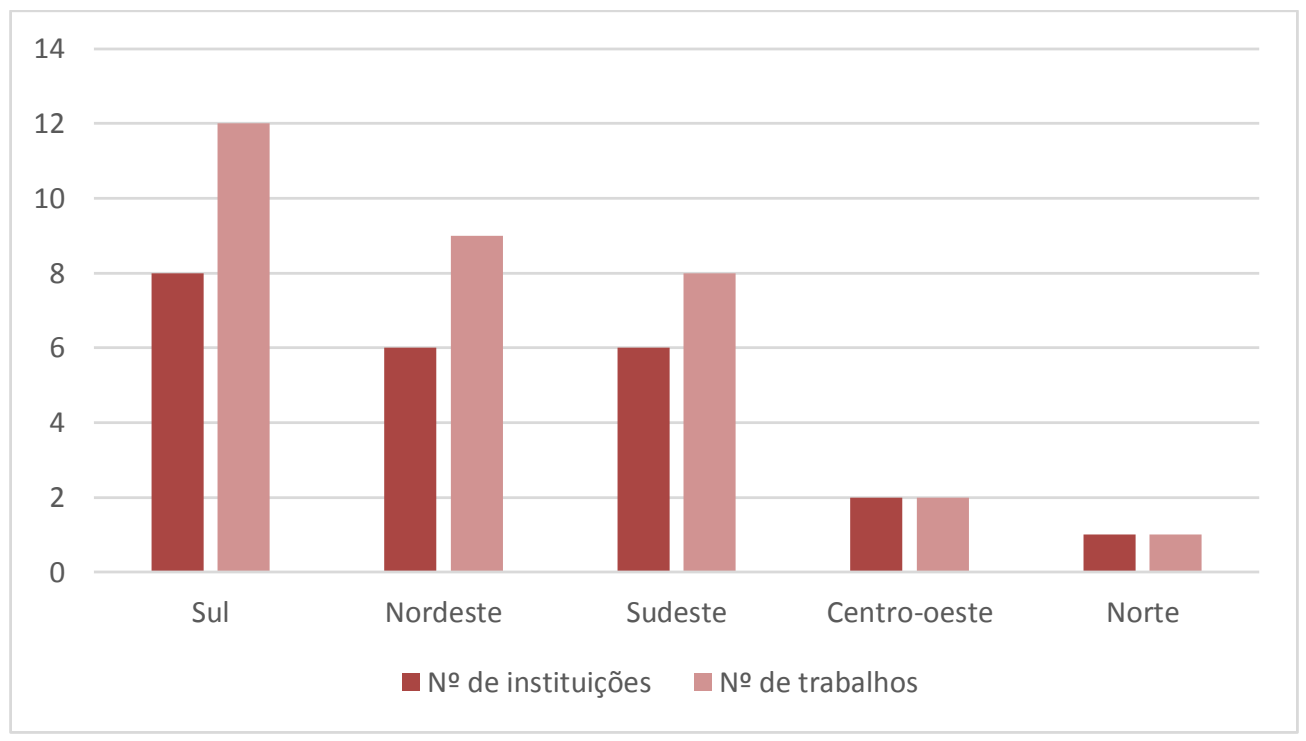

Figura 1: Número de trabalhos por região do País. 
Dentre os 30 textos analisados, 16 foram escritos individualmente e 14 foram desenvolvidos em coautoria. O número total de autores foi 43 , sendo que duas autoras publicaram mais de um trabalho e 41 autores publicaram um único trabalho nas duas publicações analisadas. Este dados nos permitem observar o interesse de diferentes autores pela temática da criatividade e das práticas criativas em educação musical, ao mesmo tempo que nos fazem refletir sobre o perfil destes autores. Entretanto, como a pesquisa abrange textos de um período curto, não é possivel apontar a continuidade ou não dos trabalhos.

A análise da formação e da atuação profissional dos autores dos textos analisados mostra a predominância de profissionais com formação em nivel de pós-graduação (32 autores), com atuação profissional no ensino superior (15 autores) e na educação básica (11 autores). Em relação aos contextos onde ocorreram as práticas descritas nos trabalhos analisados, o conjunto de textos revelou a presença das práticas criativas em contextos educacionais diversos, que compreendem o ensino superior, a educação básica e atividades extracurriculares no espaço escolar, oficinas de música e aulas de instrumento, propostas em espaços culturais e também envolvendo grupos instrumentais e corais (Tabela 2).

\begin{tabular}{l|l}
\hline \multicolumn{1}{c|}{ Contextos } & \multicolumn{1}{c}{ Trabalhos } \\
\hline & $\begin{array}{l}\text { Arantes (2017), Cotrim (2017), Domingos e Fernandino } \\
\text { (2017), Duarte e Fialho (2015), Duarte e Fialho (2017), Ferlim } \\
(2015), \text { Gomyde, Nakao e Reis (2017), Landgraf (2017), } \\
\text { Leandro e Silva (2015), Leite, Duarte e Nunes (2015), Martins } \\
\text { / Espaço escolar } \\
\text { (2015), Oliveira e Beineke (2015), Pinheiro e Luz (2015), } \\
\text { Pinheiro e Pereira Jr. (2017), Rodrigues (2015), Souza (2015), } \\
\text { Trajano (2015), Tristão e Luz (2015) e Vieira (2017) }\end{array}$ \\
\hline $\begin{array}{l}\text { Oficina / Aula } \\
\text { de instrumento }\end{array}$ & $\begin{array}{l}\text { Biazon (2015), Fonterrada (2015b), Freixedas (2015) e Lima e } \\
\text { Carvalho (2017) }\end{array}$ \\
\hline $\begin{array}{l}\text { Espaços } \\
\text { culturais / } \\
\text { Terceiro setor }\end{array}$ & Amor (2017), Amorim e Almeida (2017) e Lunelli (2017) \\
\hline $\begin{array}{l}\text { Ensino superior } \\
\text { Grupo } \\
\text { instrumental / } \\
\text { Coral }\end{array}$ & Pereira (2015) \\
\hline
\end{tabular}

Tabela 2: Contextos das práticas descritas nos trabalhos analisados.

De modo geral, observou-se que os trabalhos não têm como preocupação principal a formação de músicos, mas visam proporcionar experiências musicais diversas em contextos diversos. Entretanto, revelou-se que os 
trabalhos que envolvem criatividade na educação musical publicados nos anais dos congressos nacionais da Abem analisados vêm se desenvolvendo, em sua maioria, nos espaços de educação básica.

\section{Sobre as expressões utilizadas}

Nos trabalhos analisados foram identificadas três principais expressões relacionadas ao campo da criatividade, além do próprio termo criatividade: práticas criativas, desenvolvimento criativo e aprendizagem criativa, conforme apresenta a seguinte tabela:

\begin{tabular}{l|l}
\hline \multicolumn{1}{c|}{ Termo } & \multicolumn{1}{c}{ Trabalhos } \\
\hline Criatividade & $\begin{array}{l}\text { Amorim e Almeida (2017), Pinheiro e Luz (2015) e } \\
\text { Tristão e Beineke (2017) }\end{array}$ \\
\hline Práticas criativas & Cotrim (2017) e Fonterrada (2015b) \\
\hline $\begin{array}{l}\text { Desenvolvimento } \\
\text { criativo }\end{array}$ & Pinheiro e Luz (2015) e Tristão e Beineke (2017) \\
\hline $\begin{array}{l}\text { Aprendizagem } \\
\text { criativa }\end{array}$ & $\begin{array}{l}\text { Amorim e Almeida (2017), Domingos e Fernandino } \\
(2017), \text { Fugimoto e Beineke (2015) e Tristão e Beineke } \\
(2017)\end{array}$ \\
\hline
\end{tabular}

Tabela 3: Expressões utilizadas e conceituadas nos trabalhos analisados.

Observou-se que o termo criatividade é utilizado de modo amplo, referindo-se não somente a grandes produtos ou ideias inovadoras, mas focalizando principalmente as transformações que essa ideia ou produto pode gerar para o próprio indivíduo ou grupo gerador. O conceito de criatividade é compreendido nos trabalhos como algo que ocorre por meio das experiências e vivências sociais e culturais dos sujeitos, envolvendo processos de transformação no contexto em que ocorre (Tabela 3).

Amorim e Almeida (2017) e Tristão e Beineke (2017) fundamentam-se no conceito de criatividade elaborado por Burnard (2006, 2012), que considera, numa perspectiva sociocultural, as manifestações e as significações das relações sociais e culturais que envolvem o fazer musical criativo. Pinheiro e Luz (2015) apresentam o conceito de criatividade com base em Carneiro (2010), argumentando sobre a importância de se considerar tanto o contexto onde a criatividade emerge quanto o processo de criação de soluções apropriadas para estes.

A expressão práticas criativas em educação musical foi identificada enquanto concepção de ensino e aprendizagem em música que se refere às atividades que envolvem o fazer musical criativo, estando inserida nos 
estudos da criatividade que focalizam a educação musical e abrangem atividades e estratégias metodológicas utilizadas em práticas pedagógicas.

Fonterrada (2015b) utiliza o termo "práticas criativas" em seu trabalho, e, apesar de não o conceituar diretamente, é possivel inferir que, para a autora, as práticas criativas envolvem a criação musical e a improvisação, independentemente da fonte sonora utilizada. Segundo ela, "o domínio da criação musical e da improvisação se dá pela experiência viva, seja ao instrumento, seja com a voz e o corpo" (Fonterrada, 2015b, p. 3). Essa experiência viva a qual a autora se refere possivelmente está relacionada à espontaneidade e à inovação, pois, ao final de seu trabalho, Fonterrada reconhece a necessidade de se "trabalhar a Música de maneira espontânea e inovadora, e considerá-la um direito de todos, o que contribuirá para a construção da sociedade saudável e diversa que se quer" (Fonterrada, 2015b, p. 7).

O desenvolvimento criativo é citado pelos autores como uma atitude necessária ao desenvolvimento musical, sendo esta perspectiva uma tendência que prioriza o processo em que o produto criativo emerge. Segundo esses autores, o desenvolvimento criativo é considerado como um processo complexo que envolve os múltiplos contextos em que o aluno está inserido. Pinheiro e Luz (2015) explicam o desenvolvimento criativo como uma atitude necessária ao desenvolvimento musical, proveniente de uma tendência contemporânea que vem priorizando "o desenvolvimento do aluno (o processo) e não o valor do resultado somente (produto)" (Pinheiro; Luz, 2015, p. 4). Tendo como fundamento teórico o trabalho de Burnard (2006), Tristão e Beineke (2017) apresentam o significado do termo como:

[...] um processo complexo que inclui múltiplas culturas e esferas de influência, que iniciam no convivio familiar das crianças, que vão ampliando suas experiências sociais e, progressivamente, incluem múltiplas esferas de influência, que se movem do núcleo familiar às interfaces com outros contextos de convivência, como os círculos de amizade dentro e fora da comunidade escolar, ou contextos relacionados à etnia ou religião, ou da banda de garagem, por exemplo (Tristão; Beineke, 2017, p. 4).

A terceira expressão, identificada e conceituada em um número maior de trabalhos, foi aprendizagem criativa. Domingos e Fernandino (2017) e Amorim e Almeida (2017) conceitualizam a expressão aprendizagem criativa fundamentados em Beineke (2009, 2011, 2013, 2015). Buscando aprofundar a análise, verificou-se que os trabalhos de Fugimoto e Beineke (2015) e Tristão e Beineke (2017) baseiam-se em Craft, Cremim e Burnard (2008) e Feldman (2008) ao explicar que:

[...] o conceito de criatividade, dentro da expressão aprendizagem criativa, supõe que um esforço se torna potencialmente criativo quando se tem a intenção de 
transformar o mundo de alguma maneira, e que tal processo ou produto torna-se criativo quando é julgado como tal. Por outro lado, a aprendizagem, dentro do conceito de aprendizagem criativa, se refere aos dominios específicos que aprendemos, o que envolve a aquisição de técnicas, habilidades, informação e tecnologia que potencializam o desenvolvimento da criatividade (Tristão; Beineke, 2017, p. 4, grifos das autoras).

Essa expressão é definida de forma mais complexa, focalizando a perspectiva dos estudantes, e envolve processos de julgamento sobre o que é considerado criativo de acordo com o contexto em que a aprendizagem ocorre, com o fito de potencializar o desenvolvimento criativo em processos colaborativos de aprendizagem.

A partir dessas expressões e dos sentidos apresentados nos trabalhos analisados, observa-se que o termo criatividade é utilizado de forma ampla, incluindo as expressões práticas criativas, desenvolvimento criativo e aprendizagem criativa, cada uma delas conduzindo a definições mais precisas da criatividade na educação musical.

\section{Sobre as justificativas}

Ao analisar de que maneira as práticas criativas são entendidas e justificadas nos textos, observou-se que estas estão contextualizadas em relação a objetivos e principios mais amplos da educação musical que orientam as práticas pedagógicas relatadas. Notam-se diversos argumentos para justificar tanto a educação musical quanto a presença e as funções das práticas criativas nos contextos de educação musical. Os trabalhos argumentam que a educação musical auxilia no desenvolvimento humano individual e social e também salientam a importância de sensibilizar para o universo musical e ampliar o repertório sonoro.

Sobre a presença das práticas criativas, os trabalhos (Tabela 4) argumentam que as práticas criativas possibilitam aos estudantes se sentirem mais próximos da música reconhecida e legitimada por eles. Um argumento importante é que estas práticas são geradoras de produto musical, de modo que os alunos deveriam ter oportunidade de vivenciar diferentes modos de construção musical, permitindo que se expressem de acordo com suas próprias experiências musicais.

Observou-se uma tendência em considerar a importância da criatividade na educação musical, tendo como fundamento os estudos de Hans-Joachim Koellreutter, quando argumenta a favor do desenvolvimento amplo do ser humano; de Murray Schafer acerca da conscientização sonora; e de Keith Swanwick acerca de aspectos que envolvem a experiência e a expressão musical dos estudantes (Tabela 4). 


\begin{tabular}{|c|c|}
\hline Fundamentos & Trabalhos \\
\hline $\begin{array}{l}\text { Hans-Joachim } \\
\text { Koellreutter }\end{array}$ & $\begin{array}{l}\text { Biazon (2015), Duarte e Fialho (2017), Gomyde, Nakao e Reis } \\
\text { (2017) e Freixedas (2015) }\end{array}$ \\
\hline Murray Schafer & $\begin{array}{l}\text { Domingos e Fernandino (2017), Duarte e Fialho (2017), } \\
\text { Gomyde, Nakao e Reis (2017), Landgraf, (2017), Pereira (2015) } \\
\text { e Tristão e Beineke (2017) }\end{array}$ \\
\hline Keith Swanwick & $\begin{array}{l}\text { Cotrim (2017), Ferlim (2015), Fugimoto e Beineke (2015), } \\
\text { Leite, Duarte e Nunes (2015), Lima e Carvalho (2017), Oliveira } \\
\text { e Beineke, (2015), Pereira (2015), Pinheiro e Luz (2015), } \\
\text { Rodrigues (2015), Santos e Mendonça (2015) e Vieira (2017) }\end{array}$ \\
\hline
\end{tabular}

Tabela 4: Bases teóricas e os respectivos trabalhos que as apresentam (2019).

Os trabalhos que se fundamentam nos estudos de Koellreutter para justificar a criatividade na educação musical trazem a abordagem da improvisação livre como um meio para o desenvolvimento criativo. Biazon (2015) argumenta que a improvisação livre propicia um "ambiente de debate, diálogo e reflexão", aspectos fundamentais para a educação musical (Biazon, 2015, p. 2). Gomyde, Nakao e Reis (2017, p. 11), também com base em Koellreutter, justificam as práticas de improvisação no desenvolvimento criativo como um processo que estimula "as faculdades de percepção, comunicação, trabalho em equipe, discernimento, análise e sintese, autoconfiança, criatividade, senso crítico, sensibilidades, entre outras" (Gomyde, Nakao e Reis, 2017, p. 11).

Com base em Murray Schafer (Tabela 4), trabalhos argumentam que a educação musical tem o papel de apresentar e refletir sobre os sons existentes de um modo geral. O conceito de paisagem sonora é recorrente nos trabalhos analisados e apresenta a importância de se refletir sobre a produção sonora, buscando conscientizar os alunos da produção dos sons.

Em relação aos trabalhos que fundamentados em Keith Swanwick (Tabela 4), estes trazem como ponto principal da educação musical a composição musical enquanto processo que proporciona um aprendizado significativo, no qual os alunos se engajam na proposta baseando-se em suas próprias experiências musicais. Em relação a isso, Rodrigues (2015) afirma que esta é essencial no processo de educação musical, por ser a geradora de qualquer produto musical e por produzir a compreensão de seus elementos. Além da organização dos sons, o processo composicional envolve a motivação para o pensamento musical, a tomada de decisões e a produção de julgamentos sobre a construção da música de modo crítico e construtivo (Rodrigues, 2015, p. 9).

Por meio das justificativas apresentadas, pôde-se observar uma tendência em reconhecer a importância das práticas criativas tendo em vista 
as possibilidades que se abrem de experimentação e organização dos sons, desenvolvimento do pensamento musical e reflexão sobre os processos de produção da música. Nesse processo, também se consideram o incentivo à tomada de decisões musicais individuais e conjuntas dos alunos e o respeito às suas experiências musicais enquanto aspectos fundamentais para a aprendizagem musical.

\section{Sobre as atividades e estratégias metodológicas}

Buscando discutir as atividades e estratégias metodológicas utilizadas para implementar práticas criativas em educação musical, foram identificadas as atividades de composição, improvisação e paisagem sonora como as principais formas de potencializar o desenvolvimento criativo. Além disso, investigou-se quais as bases teóricas mais utilizadas para fundamentar as atividades e quais estratégias metodológicas vêm sendo utilizadas (Tabela $5)$.

\begin{tabular}{l|l}
\hline \multicolumn{1}{c|}{ Aspectos } & \multicolumn{1}{c}{ Tópicos } \\
\hline $\begin{array}{l}\text { Atividades que favorecem a } \\
\text { criatividade }\end{array}$ & $\begin{array}{l}\text { Arranjo } \bullet \text { Composição musical } \bullet \\
\text { Improvisação musical } \bullet \text { Jogos sonoros } \bullet \\
\text { Paisagem sonora }\end{array}$ \\
\hline $\begin{array}{l}\text { Bases teóricas mais utilizadas } \\
\text { para fundamentar as atividades }\end{array}$ & $\begin{array}{l}\text { Keith Swanwick Murray Schafer } \bullet \text { Rogério } \\
\text { Costa }\end{array}$ \\
\hline $\begin{array}{l}\text { Estratégias metodológicas em } \\
\text { destaque }\end{array}$ & $\begin{array}{l}\text { Apresentação musical } \bullet \\
\text { Interdisciplinaridade } \bullet \text { Trabalho em grupo } \bullet \\
\text { Uso de tecnologias }\end{array}$ \\
\hline
\end{tabular}

Tabela 5: Atividades, bases teóricas e estratégias metodológicas que emergem nos trabalhos.

Dentre as atividades consideradas criativas, destacaram-se os trabalhos de composição musical fundamentados teoricamente em Keith Swanwick (Swanwick, 2003; França; Swanwick, 2002). Esse trabalhos definem a composição musical de forma ampla, considerando desde as pequenas elaborações musicais até os produtos musicais mais complexos gerados em sala de aula. Autores argumentam ser possivel valorizar as experiências musicais dos alunos em um processo que envolve tomadas de decisão individual e em conjunto.

Em relação à composição musical, Oliveira e Beineke (2015), Rodrigues (2015), Fugimoto e Beineke (2015) e Martins (2015) apontam a atividade enquanto central no processo educativo musical. Segundo estes autores, a composição musical proporciona um aprendizado significativo, no qual os alunos se engajam na proposta baseando-se em suas próprias experiências musicais. Rodrigues (2015) explica que a composição se faz primordial no processo de educação musical, por ser a geradora de qualquer produto 
musical e por produzir a compreensão de seus elementos. O processo composicional envolve, além da organização dos sons, a motivação para o pensamento musical, a tomada de decisões e a produção de julgamentos sobre a construção da música de modo crítico e construtivo (Rodrigues, 2015, p. 9). Sobre isso, Oliveira e Beineke (2015) argumentam:

A composição tem o potencial de engajar o aluno criticamente
com o material musical que está sendo trabalhado. Ele
experimenta esse material buscando compreender os sons
disponiveis e faz suas escolhas por meio de uma análise crítica
baseada em suas experiências musicais (Oliveira; Beineke,
2015, p. 2).

Os trabalhos baseados em Schafer (2011a, 2011b, 1991) obtiveram destaque nas atividades que envolvem paisagem sonora. Dentre as principais ideias e atividades, observa-se o enfoque na conscientização sonora e no silêncio, abordados por meio de atividades de sonorização de histórias e imagens, jogos com paisagem sonora e elaboração de trilhas sonoras.

Em relação à composição musical e às atividades envolvendo paisagem sonora, as atividades de improvisação musical apareceram com menos destaque nos trabalhos analisados, sendo que apenas os trabalhos de Freixedas (2015) e Biazon (2015) apresentaram fundamentação teórica específica à improvisação. Esses dois trabalhos utilizam como referencial teórico a improvisação livre, na abordagem de Rogério Costa (2008). Freixedas (2015) destaca a importância da improvisação desde os primeiros contatos com o instrumento musical, salientando que, desta maneira, o instrumentista percebe com maior fluência as sonoridades do instrumento, permitindo maior liberdade. Biazon (2015) focaliza a improvisação livre como um modo de aproximação com a música que pode ser realizada por sujeitos que possuem ou não conhecimento técnico musical.

Além das atividades, foram identificadas estratégias metodológicas semelhantes nos textos analisados. Observou-se que a valorização da produção musical dos estudantes por meio de apresentações musicais e de gravações dessas produções foi evidenciada em diversos trabalhos. Alguns também focalizam as práticas interdisciplinares como modos de tornar a aprendizagem mais significativa. Entretanto, dentre essas estratégias, constatou-se que o trabalho em grupo vem sendo a mais utilizada nas práticas musicais criativas, sendo esta apresentada em todos os textos classificados como relatos de experiência. Em relação a isso, a maioria dos relatos apresenta práticas coletivas desenvolvidas em grandes grupos.

As análises acerca das atividades e estratégias metodológicas apresentadas nos trabalhos evidenciam que, apesar de serem diversas, as propostas convergem ao considerar a importância de se valorizar a produção musical dos estudantes, respeitando os contextos e as individualidades em processos que envolvem o fazer musical em conjunto. 


\section{Sobre os princípios teórico-metodológicos}

Visando compreender os princípios teórico-metodológicos que orientam as discussões sobre criatividade presentes nos textos analisados, foram identificados três princípios (Tabela 6).

\begin{tabular}{|c|c|c|}
\hline Principios & Aspectos & $\begin{array}{c}\text { Trabalhos que } \\
\text { discutem sobre o tema }\end{array}$ \\
\hline $\begin{array}{l}\text { Valorização do } \\
\text { discurso musical } \\
\text { dos alunos }\end{array}$ & $\begin{array}{l}\text { - Reconhece e legitima o que } \\
\text { os alunos compreendem } \\
\text { sobre música. } \\
\text { - Possibilita que as } \\
\text { representações pessoais e } \\
\text { sociais emerjam por meio da } \\
\text { prática musical. }\end{array}$ & $\begin{array}{l}\text { Biazon (2015), Ferlim } \\
\text { (2015), Fugimoto e } \\
\text { Beineke (2015), Martins } \\
\text { (2015), Oliveira e } \\
\text { Beineke (2015) e } \\
\text { Rodrigues }(2015)\end{array}$ \\
\hline $\begin{array}{c}\text { Professor como } \\
\text { facilitador/media } \\
\text { dor da } \\
\text { aprendizagem }\end{array}$ & $\begin{array}{l}\text { - Questionar, orientar e } \\
\text { aconselhar os alunos em } \\
\text { suas escolhas musicais. } \\
\text { - Mediar de modo a interferir } \\
\text { o minimo possivel nas } \\
\text { escolhas musicais dos } \\
\text { alunos. } \\
\text { - Motivar e estimular a } \\
\text { confiança entre professor e } \\
\text { alunos por meio de um } \\
\text { ambiente capacitador. }\end{array}$ & $\begin{array}{l}\text { Gomyde, Nakao e Reis } \\
\text { (2017), Oliveira e } \\
\text { Beineke (2015) e Tristão } \\
\text { e Beineke (2017) }\end{array}$ \\
\hline $\begin{array}{l}\text { Modos de } \\
\text { participação } \\
\text { social }\end{array}$ & $\begin{array}{l}\text { - Coparticipação: professor e } \\
\text { alunos aprendendo, } \\
\text { discutindo e fazendo música } \\
\text { uns com os outros. } \\
\text { - Participação coletiva: } \\
\text { envolvimento de todos os } \\
\text { alunos em práticas criativas } \\
\text { em música. } \\
\text { - Participação colaborativa: } \\
\text { alunos atuando em pares e } \\
\text { pequenos grupos em um } \\
\text { processo criativo. }\end{array}$ & $\begin{array}{l}\text { Biazon (2015), Ferlim } \\
\text { (2015), Fugimoto e } \\
\text { Beineke (2015), Leandro } \\
\text { e Silva (2015), Lunelli } \\
\text { (2015), Oliveira e } \\
\text { Beineke (2015), } \\
\text { Pinheiro e Luz (2015), } \\
\text { Rodrigues (2015), } \\
\text { Santos e Mendonça } \\
\text { (2015), Trajano (2015), } \\
\text { Tristão e Beineke (2017) } \\
\text { e Tristão e Luz (2015) }\end{array}$ \\
\hline
\end{tabular}

Tabela 6: Principios teórico-metodológicos que orientam as discussões nos trabalhos analisados.

O primeiro princípio refere-se à valorização do discurso musical dos alunos, compreendendo que cada sujeito vivencia a música de diferentes maneiras e participa de contextos musicais variados, que somam experiências, influências e preferências musicais. Essa valorização está relacionada ao papel do professor, que, de acordo com os textos analisados, tem a função de atuar como uma mediadora ou mediador. Conforme explicam os autores, o seu papel é o de questionar, aconselhar e orientar os estudantes, 
buscando interferir o minimo possivel nas escolhas musicais dos alunos. Dessa forma, a professora ou o professor estão atentos à oportunização de um ambiente de construção do conhecimento em que os estudantes possam colocar suas ideias perante o grupo e sentem-se à vontade para tal.

Agindo dessa maneira, a professora ou o professor motiva e estimula a confiança entre estudantes e professor(a), proporcionando o que Craft (2010) chama de ambiente capacitador, onde a ideia central é promover atividades que têm certo grau de estruturação, para que os alunos não se sintam perdidos e, ao mesmo tempo, permitam que elas e eles tenham liberdade para expressarem suas ideias, sem serem condicionados por normas muito fechadas.

O terceiro princípio identificado refere-se aos modos de participação social, explicando sobre o trabalho em grupo e suas possibilidades em sala de aula. Jeffrey e Woods (2009) dividem o trabalho em grupo em três modos de participação, sendo a coparticipação quando estudantes e professores trabalham juntos, a participação coletiva quando alunos produzem algo junto e a participação colaborativa quando os estudantes se dividem em pequenos grupos para produzirem algo.

Nos textos analisados verificou-se que a maioria dos trabalhos relatam práticas coletivas, envolvendo todos os estudantes em um processo de produção musical, enquanto formas coparticipativas e colaborativas são menos frequentes. Sobre isso, é importante destacar que a prática coletiva, por ocorrer em grandes grupos, oferece um espaço limitado no que diz respeito ao julgamento pessoal. Neste sentido, é importante que haja mais espaço para participações em pequenos grupos nos processos de ensino e aprendizagem em música. Conforme explica Swanwick (2003), quando a proposta ocorre em pequenos grupos, os estudantes "trarão suas próprias interpretações e tomarão suas próprias decisões musicais em muitos níveis. Eles começarão a se 'apropriar' da música por eles mesmos" (Swanwick, 2003, p. 67).

\section{CONSIDERAÇÕES FINAIS}

O conjunto de resultados desta pesquisa permite tecer algumas considerações sobre como vêm se configurando os estudos e pesquisas sobre criatividade na educação musical no Brasil. Em primeiro lugar, foi possivel identificar um entendimento em comum de que as práticas criativas são necessárias ao desenvolvimento da educação musical, devendo valorizar a produção e o discurso musical dos estudantes por meio de processos que envolvam o fazer musical coletivo e criativo. Essas ideias parecem responder positivamente aos esforços que pesquisadoras e pesquisadores brasileiros vêm envidando nesse sentido, ao longo dos últimos anos (Beineke, 2015, 2009, 2008; Brito, 2015, 2007; Fonterrada, 2015a). Nesse sentido, percebese que grande parte dos textos analisados apresentam essas pesquisas enquanto fontes teóricas no Brasil. 
Em segundo lugar, notou-se que, em grande parte dos trabalhos, os referenciais teóricos são abordados como fonte para o planejamento de atividades e como base para as estratégias metodológicas. Entretanto, percebe-se que não é enfatizada a utilização de referenciais teóricos para discutir e problematizar essas práticas. Em relação às experiências relatadas nos textos, percebe-se que estas compartilham muitos referenciais teóricos, possivelmente porque são escassas as fontes no Brasil que tratam exclusivamente dessa temática.

Observou-se que as problematizações entre as práticas relatadas e o campo teórico, quando apresentadas nos trabalhos, por vezes não permitem uma visão mais ampla de como os resultados se conectam ao campo da criatividade. Muitas vezes estas consistem em reflexões que se encerram nos âmbitos em que foram desenvolvidas, focalizando as contribuições dos trabalhos especificamente para os sujeitos e contextos onde a prática pedagógica aconteceu. Entretanto, é necessário considerar que a maioria dos trabalhos aqui analisados apresenta relatos de experiência que se caracterizam por não ter como foco a preocupação em contribuir teoricamente com a área, ou, ainda, em pesquisas em andamento que ainda não apresentavam análise e reflexão teórica mais aprofundadas.

Concluindo, foi possivel delinear um campo emergente de estudos que focaliza as práticas criativas em educação musical, contribuindo ao apresentar o tema como um campo fértil de estudo que busca valorizar as experiências culturais e sociais dos alunos, que permite abordagens teóricas e metodológicas variadas, que pode proporcionar uma aprendizagem e desenvolvimento musicais mais amplos e contextualizados às necessidades de crianças e jovens. Acredita-se que, como consequência, será possível valorizar e reconhecer cada vez mais os discursos e as identidades musicais dos estudantes, considerando as aprendizagens, os significados e as ideias que emergem das práticas criativas, em todo o seu potencial crítico e transformador.

\section{REFERENCIAS}

ABEM. Politicas Editoriais. Revista da Abem, [s.1., s.d.], Foco e Escopo. Disponivel em: http://www.abemeducacaomusical.com.br/revistas/revistaabem/index.php / revistaabem/about/editorialPolicies\#focusAndScope. Acesso em: 10 maio 2019.

ALENCAR, E. S. de. Criatividade no contexto educacional: três décadas de pesquisa. Psicologia: Teoria e Pesquisa, v. 23, n. especial, p. 45-49, 2007.

AMORIM, Q. P. de B. S.; ALMEIDA, C. M. G. de. Educação musical no terceiro setor: reflexões sobre os processos de significação e criatividade musical. In: CONGRESSO NACIONAL DA ASSOCIAÇÃO BRASILEIRA DE EDUCAÇÃO MUSICAL, 23., 2017, Natal. Anais [...]. Natal: Abem, 2017. v. 2. 
BEINEKE, V. Aprendizagem criativa na escola: um olhar para a perspectiva das crianças sobre suas práticas musicais. Revista da ABEM, Londrina, v. 19, n. 26, p. 92-104, jan./jul. 2011.

. A composição no ensino de música: perspectivas de pesquisa e tendências atuais. Revista da ABEM, Porto Alegre, v. 20, p. 19-32, set. 2008.

Ensino musical criativo em atividades de composição na escola

básica. Revista da ABEM, Londrina, v. 23, n. 34, p. 42-57, jan./jul. 2015.

Processos intersubjetivos na composição musical de crianças: um estudo sobre aprendizagem criativa. 2009. Tese (Doutorado em Música) Programa de Pós-Graduação em Música, Instituto de Artes, Universidade Federal do Rio Grande do Sul, Porto Alegre, 2009.

BIAZON, S. Improvisação livre a partir de vídeos: estratégias de realização, considerações e hipóteses. In: CONGRESSO NACIONAL DA ASSOCIAÇÃO BRASILEIRA DE EDUCAÇÃO MUSICAL, 22., 2015, Natal. Anais [...]. Natal: Abem, 2015. v. 1.

BRITO, Teca Alencar de. Ferramentas com brinquedos: a caixa da música. Revista da ABEM, Porto Alegre, v. 24, p. 89-93, set. 2010.

Hans-Joachim Koellreutter: músico e educador musical menor. Revista da Abem, Londrina, v. 33, n. 35, p.11-23, jul./dez. 2015.

Por uma educação musical do pensamento: novas estratégias de comunicação. 2007. 288 f. Tese (Doutorado em Comunicação e Semiótica) Pontifícia Universidade Católica de São Paulo, São Paulo, 2007.

Burnard, P. Rethinking 'musical creativity' and the notion of multiple creativities in music. In: ODENA, O. Musical Creativity: insights from music education research. England: Ashgate Publishing, 2012. p. 5-27.

. How children ascribe meaning to improvisation and composition: rethinking pedagogy in music education. Music Education Research, v. 2, n. 1,2000 .

. Understanding children's meaning-making as composers. In: DELIĖGE, I.; WIGGINS, G. A. (Eds.). Musical Creativity: multidisciplinary research in theory and practice. New York: Psychology Press, 2006. p. 111133.

CHARMAZ, K. A construção da teoria fundamentada: guia prático para análise qualitativa. Porto Alegre: Artmed, 2009.

COSTA, R. L. M. da. A ideia de corpo e a configuração do ambiente da improvisação musical. Opus, v. 14, n. 2, dez. 2008.

COTRIM, R. M. B. Educação musical em ambiente de estúdio eletroacústico: uma perspectiva para as práticas musicais criativas. In: CONGRESSO 
NACIONAL DA ASSOCIAÇÃO BRASILEIRA DE EDUCAÇÃO MUSICAL, 23., 2017. Natal. Anais [...]. Natal: Abem, 2017. v. 2.

CRAFT, A. A criatividade e os ambientes da educação infantil. In: PAIGESMITH, A.; CRAFT, A. O desenvolvimento da prática reflexiva na educação infantil. Porto Alegre: Artmed, 2010. p. 120-135.

CRAFT, A. Creativity in Schools: tensions and dilemas. London: Routledge, 2005.

CRAFT, A.; PAIGE-SMITH, A. O que é preciso para que sejamos profissionais que refletem sobre a prática na educação infantil? In: PAIGE-SMITH, A.; CRAFT, A. O desenvolvimento da prática reflexiva na educação infantil. Porto Alegre: Artmed, 2010.

CSIKSZENTMIHALYI, M. Creativity: flow and the psychology of discovery and invention. New York: Harper Perennial, 1997.

DEL BEN, L. Produção científica em educação musical e seus impactos nas políticas e práticas educacionais. Revista da Abem, Porto Alegre, v. 16, n. 16, p. 57-64, mar. 2007.

DOMINGOS, D.; FERNANDINO, J. Processos de criação musical: construindo caminhos no Programa Escola Integrada. In: CONGRESSO NACIONAL DA ASSOCIAÇÃO BRASILEIRA DE EDUCAÇÃO MUSICAL, 23., 2017, Natal. Anais [...]. Natal: Abem, 2017. v. 2.

DUARTE, K. R. P.; FIALHO, V. M. Apreciação e composição de música contemporânea na escola. In: CONGRESSO NACIONAL DA ASSOCIAÇÃO BRASILEIRA DE EDUCAÇÃO MUSICAL, 23., 2017, Natal. Anais [...]. Natal: Abem, 2017. v. 2.

FERLIM, U. D. C. Circlesongs: uma abordagem de prática musical criativa e colaborativa. In: CONGRESSO NACIONAL DA ASSOCIAÇÃO BRASILEIRA DE EDUCAÇÃO MUSICAL, 22., 2015, Natal. Anais [...]. Natal: Abem, 2015. V. 1 .

FONTERRADA, Ma. T. de O.; MUSICAL, Grupo de Estudos e Pesquisa em Educação. Práticas criativas no ensino e aprendizagem da música - um estudo dos artigos dos Anais e Revistas da ABEM. In: CONGRESSO NACIONAL DA ASSOCIAÇÃO BRASILEIRA DE EDUCAÇÃO MUSICAL, 22., 2015, Natal. Anais [...]. Natal: Abem, 2015b. v. 1.

FONTERRADA, M. T. de O. Ciranda de sons: práticas criativas em educação musical. São Paulo: Editora UNESP Digital, 2015a.

FRANÇA, C. C.; SWANWICK, K. Composição, apreciação e performance na educação musical: teoria, pesquisa e prática. Em Pauta, v. 13, n. 21, p. 541, 2002. 
FREGA, A. L. Evaluar experiencias de creatividad musical en el aula: informe sobre una línea de investigación. Revista da $A B E M$, Porto Alegre, v. 24 , p. 13-24, set. 2010.

FREIXEDAS, C. M. O desenvolvimento de aspectos humanos e técnicos através do ensino da flauta doce. In: CONGRESSO NACIONAL DA ASSOCIAÇÃO BRASILEIRA DE EDUCAÇÃO MUSICAL, 22., 2015, Natal. Anais [...]. Natal: Abem, 2015. v. 1.

FUGIMOTO, T. A. da C.; BEINEKE, V. Educação musical com idosas: processos colaborativos de composição musical. In: CONGRESSO NACIONAL DA ASSOCIAÇÃO BRASILEIRA DE EDUCAÇÃO MUSICAL, 22., 2015, Natal. Anais [...]. Natal: Abem, 2015. v. 1.

GIBBS, G. Análise de dados qualitativos. Porto Alegre: Artmed, 2009. Trad. Roberto Cataldo Costa.

GOMYDE, L. D. C., NAKAO, J. V. D.; REIS, L. A. dos. O ensino de música e suas aprendizagens na escola: práticas criativas em sala de aula. In: CONGRESSO NACIONAL DA ASSOCIAÇÃO BRASILEIRA DE EDUCAÇÃO MUSICAL, 23., 2017, Natal. Anais [...]. Natal: Abem, 2017. v. 2.

GRAY, D. E.. Pesquisa no mundo real. 2. ed. Trad. Roberto Cataldo Costa. Porto Alegre: Penso, 2012.

JEFFREY, B.; WOODS, P. Creative learning in the Primary School. London: Routledge, 2009.

LANDGRAF, R. M. Paisagem sonora na educação infantil: o caminhar para uma escuta pensante através de ações do PIBID. In: CONGRESSO NACIONAL DA ASSOCIAÇÃO BRASILEIRA DE EDUCAÇÃO MUSICAL, 23., 2017, Natal. Anais [...]. Natal: Abem, 2017. v. 2.

LEANDRO, A. C. da S.; SILVA, N. F. de S. O jovem, a educação básica e o processo colaborativo: um relato de experiência das disciplinas de Atividades Orientadas III e Estágio Supervisionado IV. In: CONGRESSO NACIONAL DA ASSOCIAÇÃO BRASILEIRA DE EDUCAÇÃO MUSICAL, 22., 2015, Natal. Anais [...]. Natal: Abem, 2015. v. 1.

LEITE, J. C.; DUARTE, K.; NUNES, H. de S. A composição de microcanções na escola básica: um relato de experiência. In: CONGRESSO NACIONAL DA ASSOCIAÇÃO BRASILEIRA DE EDUCAÇÃO MUSICAL, 22., 2015, Natal. Anais [...]. Natal: Abem, 2015. v. 1.

LIMA, J. C. de; CARVALHO, V. L. de. O compositor em cada um: relatos sobre a Experiência de ensino do violão básico e da composição popular num âmbito não formal de ensino. In: CONGRESSO NACIONAL DA ASSOCIAÇÃO BRASILEIRA DE EDUCAÇÃO MUSICAL, 23., 2017, Natal. Anais [...]. Natal: Abem, 2017. v. 2. 
LIMA, T. C. S. de; MIOTO, R. C. T. Procedimentos metodológicos na construção do conhecimento científico: a pesquisa bibliográfica. Revista Katál, Florianópolis, v. 10, n. especial, p. 37-45, 2007.

LUBART, T. Psicologia da Criatividade. Trad. Márcia Conceição Machado Moraes. Porto Alegre: Artmed, 2007b.

LUNELLI, D. C. Oficina de ritmos da cultura popular: religiosidades afrobrasileiras em pauta. In: CONGRESSO NACIONAL DA ASSOCIAÇÃO BRASILEIRA DE EDUCAÇÃO MUSICAL, 22., 2015, Natal. Anais [...]. Natal: Abem, 2015. v. 1.

MARCONI, M. de A.; LAKATOS, Eva Maria. Fundamentos da metodologia científica. São Paulo: Atlas, 2003.

MARTINS, Á. da C. Linhas, vozes e tracks: a textura na composição musical de crianças. In: CONGRESSO NACIONAL DA ASSOCIAÇÃO BRASILEIRA DE EDUCAÇÃO MUSICAL, 22., 2015, Natal. Anais [...]. Natal: Abem, 2015. v. 1.

NAZARIO, L. da C.; MANNIS, J. A. Entre explorações e invenções: vislumbrando um modelo referencial para o desenvolvimento criativo em ambientes de ensino coletivo. Revista da ABEM, Londrina, v. 22, n. 23, p. 65-76, jan./jun. 2014.

OLIVEIRA, R. D. de O.; BEINEKE, V. Composição na Educação de Jovens e Adultos: mobilizando ideias de música. In: CONGRESSO NACIONAL DA ASSOCIAÇÃO BRASILEIRA DE EDUCAÇÃO MUSICAL, 22., 2015, Natal. Anais [...]. Natal: Abem, 2015. v. 1.

PEREIRA JR, G. A.; HARTMANN, E. Sobre o ensino da técnica de construção de melodias: considerações sobre o método pedagógico no Fundamentos da composição musical, de Arnold Schoenberg. Revista da Abem, Londrina, v. 25, n. 36, p. 115-131, jul./dez. 2017.

PEREIRA, L. R. O. de M. Educação musical no curso de Licenciatura em educação no campo: um relato de experiência. In: CONGRESSO NACIONAL DA ASSOCIAÇÃO BRASILEIRA DE EDUCAÇÃO MUSICAL, 22., 2015, Natal. Anais [...]. Natal: Abem, 2015. v. 1.

PINHEIRO, E. M.; PEREIRA JR, M. F. Na trilha da história: os caminhos em que a música pode nos levar. In: CONGRESSO NACIONAL DA ASSOCIAÇÃO BRASILEIRA DE EDUCAÇÃO MUSICAL, 23., 2017, Natal. Anais [...]. Natal: Abem, 2017. v. 2.

PINHEIRO, T. P. B. C.; LUZ, J. A. de M. Criação musical com a flauta doce: Uma experiência com alunos do quinto ano do Ensino Fundamental da Escola de Aplicação da UFPA. In: CONGRESSO NACIONAL DA ASSOCIAÇÃO BRASILEIRA DE EDUCAÇÃO MUSICAL, 22., 2015, Natal. Anais [...]. Natal: Abem, 2015. v. 1. 
RODRIGUES, V. P. Atividade de composição musical coletiva no ensino fundamental municipal da cidade do Rio de Janeiro: um relato de experiência. In: CONGRESSO NACIONAL DA ASSOCIAÇÃO BRASILEIRA DE EDUCAÇÃO MUSICAL, 22., 2015, Natal. Anais [...]. Natal: Abem, 2015. v. 1.

SANTOS, C. F. dos S.; MENDONÇA, Artur G. "O tambor tá tocando que tambor bonito": a criação de um repertório percussivo. In: CONGRESSO NACIONAL DA ASSOCIAÇÃO BRASILEIRA DE EDUCAÇÃO MUSICAL, 22., 2015, Natal. Anais [...]. Natal: Abem, 2015. v. 1.

SCHAFER, M. O ouvido pensante. Trad. Marisa Fonterrada, Magda Gomes da Silva e Maria Lúcia Pascoal. São Paulo: Unesp, 1991.

- A afinação do mundo: uma exploração pioneira pela história passada e pelo atual estado negligenciado aspecto do nosso ambiente: a paisagem sonora. Trad. Marisa Trench de Oliveira Fonterrada. 2. ed. São Paulo: Editora UNESP, 2011 a.

Educação Sonora. São Paulo: Melhoramentos, 2011b.

SWANWICK, K. Ensinando música musicalmente. São Paulo: Moderna, 2003.

TAFURI, J. Processes and teaching strategies in music improvisation with children. In: DELIĖGE, Irène; WIGGINS, Geraint A. (Eds.). Musical creativity: multidisciplinary research in theory and practice. New York: Psychology Press, 2006. p. 134-157.

TRAJANO, T. da C. Educação musical e a prática de projetos: um relato de experiência sobre o processo de criação de um musical com alunos do Instituto Federal do Maranhão - Campus Centro Histórico. In: CONGRESSO NACIONAL DA ASSOCIAÇÃO BRASILEIRA DE EDUCAÇÃO MUSICAL, 22., 2015, Natal. Anais [...]. Natal: Abem, 2015. v. 1.

TRISTÃO, C. R. Y.; BEINEKE, V. Um barulho estranho: relato de experiência com uma turma do $3^{\circ}$ ano do ensino fundamental. In: CONGRESSO NACIONAL DA ASSOCIAÇÃO BRASILEIRA DE EDUCAÇÃO MUSICAL, 23., 2017, Natal. Anais [...]. Natal: Abem, 2017. v. 2.

TRISTÃO, C. R. Y.; LUZ, S. D. da. Sonoplastia e trilha sonora: uma experiência interdisciplinar com alunos do $8^{\circ}$ ano de uma escola municipal. In: CONGRESSO NACIONAL DA ASSOCIAÇÃO BRASILEIRA DE EDUCAÇÃO MUSICAL, 22., 2015, Natal. Anais [...]. Natal: Abem, 2015. v. 1.

VIEIRA, D. Entre risos e rimas: criação musical e protagonismo em classes de EJA. In: CONGRESSO NACIONAL DA ASSOCIAÇÃO BRASILEIRA DE EDUCAÇÃO MUSICAL, 23., 2017, Natal. Anais [...]. Natal: Abem, 2017. v. 2.

VIEIRA, R. A criatividade no foco da educação musical. 2014. Dissertação (Mestrado em Música) - Programa de Pós-Graduação em Música, Centro de Letras e Artes, Universidade Federal do Estado do Rio de Janeiro, Rio de Janeiro, 2014. 
VISNADI, G. F.; BEINEKE, V. "De amizade, letras e ritmos": ideias das crianças sobre a composição musical na escola básica. Revista da Abem, Londrina, v. 24, n. 36, p. 71-84, jan./jun. 2016.

WAZLAWICK, P.; MAHEIRIE, K. Sujeitos e músicas em movimentos criadores compondo comunidades de prática musical. Revista da Abem, Porto Alegre, v. 21, p. 103-112, mar. 2009.

WEBSTER, P. Creative Thinking in Music, Twenty-Five Years On. Music Educators Journal, California, p. 26-32, mar. 2016.

\section{ANEXO I - LISTA DE TRABALHOS SELECIONADOS PARA A PESQUISA}

\begin{tabular}{l|c|c|c}
\hline \multicolumn{4}{c}{ PROJETO DE PESQUISA OU PESQUISA EM ANDAMENTO } \\
\hline Ano & Autores(as) & Título & Instituições \\
\hline \multirow{2}{*}{2015} & BIAZON, Stênio & $\begin{array}{c}\text { Improvisação livre a partir de } \\
\text { videos: estratégias de } \\
\text { realização, considerações e } \\
\text { hipóteses }\end{array}$ & USP/SP \\
\hline \multirow{2}{*}{2015} & $\begin{array}{c}\text { FREIXEDAS, } \\
\text { Cláudia M. }\end{array}$ & $\begin{array}{c}\text { O desenvolvimento de } \\
\text { atravectos humanos e técnicos ensino da flauta } \\
\text { doce }\end{array}$ & USP/SP \\
& $\begin{array}{c}\text { OLIVEIRA, Rafael D. } \\
\text { de O.; BEINEKE, } \\
\text { Viviane }\end{array}$ & $\begin{array}{c}\text { Composição na educação de } \\
\text { jovens e adultos: mobilizando } \\
\text { ideias de música }\end{array}$ & UDESC/SC \\
\hline \multirow{2}{*}{2017} & $\begin{array}{c}\text { AMORIM, Quézia P. } \\
\text { de B. S.; ALMEIDA, } \\
\text { Cristiane M. G. de }\end{array}$ & $\begin{array}{c}\text { Educação musical no terceiro } \\
\text { setor: reflexões sobre os } \\
\text { processos de significação e } \\
\text { criatividade musical }\end{array}$ & UFPB/PB \\
& $\begin{array}{c}\text { ARANTES, Lucielle } \\
\text { F. }\end{array}$ & $\begin{array}{c}\text { Didática desenvolvimental da } \\
\text { subjetividade: uma proposta } \\
\text { ao ensino de Música na } \\
\text { escola }\end{array}$ & UFU/MG \\
\hline
\end{tabular}




\begin{tabular}{|c|c|c|c|}
\hline 2017 & DIDIER, Adriana R. & $\begin{array}{l}\text { Jesualdo: um educador } \\
\text { uruguaio em busca da } \\
\text { expressão criadora }\end{array}$ & UNIRIO/RJ \\
\hline \multicolumn{4}{|c|}{ PESQUISA CONCLUÍDA } \\
\hline Ano & Autores(as) & Titulo & Instituições \\
\hline 2015 & $\begin{array}{c}\text { FONTERRADA, } \\
\text { Marisa T. de O.; } \\
\text { GEPEM - Grupo de } \\
\text { Estudo e Pesquisa } \\
\text { em Educação } \\
\text { Musical }^{5}\end{array}$ & $\begin{array}{l}\text { Práticas criativas no ensino e } \\
\text { aprendizagem da música - } \\
\text { um estudo dos artigos dos } \\
\text { Anais e Revistas da ABEM }\end{array}$ & UNESP/SP \\
\hline 2015 & $\begin{array}{l}\text { FUGIMOTO, Tatiane } \\
\text { A. da C.; BEINEKE, } \\
\text { Viviane }\end{array}$ & $\begin{array}{c}\text { Educação musical com } \\
\text { idosas: processos } \\
\text { colaborativos de composição } \\
\text { musical }\end{array}$ & UDESC/SC \\
\hline 2015 & $\begin{array}{c}\text { MARTINS, Áudrea da } \\
\text { C. }\end{array}$ & $\begin{array}{l}\text { Linhas, vozes e tracks: a } \\
\text { textura na composição } \\
\text { musical de crianças }\end{array}$ & UFRGS/RS \\
\hline 2015 & SOUZA, Fernanda & $\begin{array}{l}\text { Os processos criativos no } \\
\text { contexto dos jogos de mãos }\end{array}$ & UFPR/PR \\
\hline 2017 & AMOR, Juracy do & $\begin{array}{l}\text { Ensino-aprendizagem } \\
\text { musical no Circo Picolino }\end{array}$ & UFBA/BA \\
\hline 2017 & $\begin{array}{c}\text { COTRIM, Ricardo M. } \\
\text { B. }\end{array}$ & $\begin{array}{c}\text { Educação musical em } \\
\text { ambiente de estúdio } \\
\text { eletroacústico: uma } \\
\text { perspectiva para as práticas } \\
\text { musicais criativas }\end{array}$ & UNIRIO/RJ \\
\hline
\end{tabular}

RELATOS DE EXPERIÊNCIA

\begin{tabular}{c|c|c|c}
\hline Ano & Autores(as) & Título & Instituições \\
\hline 2015 & $\begin{array}{c}\text { FERLIM, Uliana D. } \\
\text { C. }\end{array}$ & $\begin{array}{c}\text { Circlesongs: uma abordagem } \\
\text { de prática musical criativa e } \\
\text { colaborativa }\end{array}$ & UnB/DF \\
\hline 2015 & $\begin{array}{c}\text { LEANDRO, Anna C. } \\
\text { da S.; SILVA, Nayara } \\
\text { F. de S. }\end{array}$ & $\begin{array}{c}\text { O jovem, a educação básica e } \\
\text { o processo colaborativo: um } \\
\text { relato de experiência das }\end{array}$ & UFRN/RN \\
\hline
\end{tabular}

${ }^{5}$ Para as citações deste trabalho nesta pesquisa será utilizado apenas Fonterrada (2015b), visto que a coautoria consiste em um grupo de pesquisa. 


\begin{tabular}{|c|c|c|c|}
\hline & & $\begin{array}{l}\text { disciplinas de Atividades } \\
\text { Orientadas III e Estágio } \\
\text { Supervisionado IV }\end{array}$ & \\
\hline 2015 & $\begin{array}{l}\text { LEITE, Jaqueline C.; } \\
\text { DUARTE, Kátia; } \\
\text { NUNES, Helena de } \\
\text { S. }\end{array}$ & $\begin{array}{c}\text { A composição de } \\
\text { microcanções na escola } \\
\text { básica: um relato de } \\
\text { experiência }\end{array}$ & $\begin{array}{c}\text { UFBA/BA } \\
\text { UFRGS/RS }\end{array}$ \\
\hline 2015 & LUNELLI, Diego C. & $\begin{array}{c}\text { Oficina de ritmos da cultura } \\
\text { popular: religiosidades afro- } \\
\text { brasileiras em pauta }\end{array}$ & UCS/RS \\
\hline 2015 & $\begin{array}{c}\text { PEREIRA, Luana R. } \\
\text { O. de M. }\end{array}$ & $\begin{array}{l}\text { Educação musical no curso } \\
\text { de Licenciatura em Educação } \\
\text { no Campo: um relato de } \\
\text { experiência }\end{array}$ & UFMS/MS \\
\hline 2015 & $\begin{array}{l}\text { PINHEIRO, Thaynah } \\
\text { P. B. C.; LUZ, } \\
\text { Jefferson A. de M. }\end{array}$ & $\begin{array}{l}\text { Criação musical com a flauta } \\
\text { doce: uma experiência com } \\
\text { alunos do quinto ano do } \\
\text { ensino fundamental da } \\
\text { Escola de Aplicação da UFPA }\end{array}$ & UFPA/PA \\
\hline 2015 & $\begin{array}{l}\text { RODRIGUES, } \\
\text { Vinícius P. }\end{array}$ & $\begin{array}{l}\text { Atividade de composição } \\
\text { musical coletiva no ensino } \\
\text { fundamental municipal da } \\
\text { cidade do Rio de Janeiro: um } \\
\text { relato de experiência }\end{array}$ & $\begin{array}{c}\text { Secretaria } \\
\text { Municipal de } \\
\text { Educação do Rio de } \\
\text { Janeiro/RJ }\end{array}$ \\
\hline 2015 & $\begin{array}{l}\text { SANTOS, Catherine } \\
\text { F. dos Santos; } \\
\text { MENDONÇA, Artur } \\
\text { G. }\end{array}$ & $\begin{array}{l}\text { “O tambor tá tocando que } \\
\text { tambor bonito": a criação de } \\
\text { um repertório percussivo }\end{array}$ & $\mathrm{UFCE} / \mathrm{CE}$ \\
\hline 2015 & $\begin{array}{c}\text { TRAJANO, Tayane } \\
\text { da C. }\end{array}$ & $\begin{array}{l}\text { Educação musical e a prática } \\
\text { de projetos: um relato de } \\
\text { experiência sobre o processo } \\
\text { de criação de um musical } \\
\text { com alunos do Instituto } \\
\text { Federal do Maranhão - } \\
\text { Campus Centro Histórico }\end{array}$ & IFMA/MA \\
\hline 2015 & $\begin{array}{l}\text { TRISTÃO, Claudia R. } \\
\text { Y.; LUZ, Sandra D. } \\
\text { da }\end{array}$ & $\begin{array}{c}\text { Sonoplastia e trilha sonora: } \\
\text { uma experiência } \\
\text { interdisciplinar com alunos } \\
\text { do } 8^{\circ} \text { ano de uma escola } \\
\text { municipal }\end{array}$ & $\begin{array}{l}\text { EBM Virgílio dos } \\
\text { Reis Várzea/SC }\end{array}$ \\
\hline
\end{tabular}




\begin{tabular}{|c|c|c|c|}
\hline 2017 & $\begin{array}{l}\text { DOMINGOS, } \\
\text { Douglas; } \\
\text { FERNANDINO, } \\
\text { Jussara }\end{array}$ & $\begin{array}{l}\text { Processos de criação musical: } \\
\text { construindo caminhos no } \\
\text { Programa Escola Integrada }\end{array}$ & UFMG / MG \\
\hline 2017 & $\begin{array}{l}\text { DUARTE, Karine R. } \\
\text { P.; FIALHO, Vania } \\
\text { M. }\end{array}$ & $\begin{array}{l}\text { Apreciação e composição de } \\
\text { música contemporânea na } \\
\text { escola }\end{array}$ & UEM / PR \\
\hline 2017 & $\begin{array}{l}\text { GOMYDE, Luana D. } \\
\text { C., NAKAO, João V. } \\
\text { D.; REIS, Leandro A. } \\
\text { dos }\end{array}$ & $\begin{array}{l}\text { O ensino de Música e suas } \\
\text { aprendizagens na escola: } \\
\text { práticas criativas em sala de } \\
\text { aula }\end{array}$ & UEL/PR \\
\hline 2017 & $\begin{array}{c}\text { LANDGRAF, Renata } \\
\text { M. }\end{array}$ & $\begin{array}{l}\text { Paisagem sonora na } \\
\text { educação infantil: o caminhar } \\
\text { para uma escuta pensante } \\
\text { através de ações do PIBID }\end{array}$ & UEL/PR \\
\hline 2017 & $\begin{array}{l}\text { LIMA, Júlio C. de; } \\
\text { CARVALHO, Valéria } \\
\text { L. de }\end{array}$ & $\begin{array}{l}\text { O compositor em cada um: } \\
\text { relatos sobre a experiência de } \\
\text { ensino do violão básico e da } \\
\text { composição popular num } \\
\text { âmbito não formal de ensino }\end{array}$ & UFRN/RN \\
\hline 2017 & $\begin{array}{l}\text { PINHEIRO, Elton M.; } \\
\text { PEREIRA JR, } \\
\text { Melquíades F. }\end{array}$ & $\begin{array}{c}\text { Na trilha da história: os } \\
\text { caminhos em que a música } \\
\text { pode nos levar }\end{array}$ & UNIVALI/SC \\
\hline 2017 & $\begin{array}{l}\text { TRISTÃO, Claudia R. } \\
\text { Y.; BEINEKE, } \\
\text { Viviane }\end{array}$ & $\begin{array}{l}\text { Um barulho estranho: relato } \\
\text { de experiência com uma } \\
\text { turma do } 3^{\circ} \text { ano do ensino } \\
\text { fundamental }\end{array}$ & $\begin{array}{c}\text { Secretaria } \\
\text { Municipal de } \\
\text { Educação de } \\
\text { Florianópolis/SC } \\
\text { UDESC/SC }\end{array}$ \\
\hline 2017 & VIEIRA, Djenane & $\begin{array}{l}\text { Entre risos e rimas: criação } \\
\text { musical e protagonismo em } \\
\text { classes de EJA }\end{array}$ & UFBA/BA \\
\hline
\end{tabular}


Lia Viégas Mariz de Oliveira Pelizzon é Mestra em Música na subárea Educação Musical pela Universidade do Estado de Santa Catarina, atua como professora-tutora no Centro Universitário Claretiano no polo de Florianópolis/SC e como professora de música em escola da rede privada de educação básica. https://orcid.org/0000-0003-1699-7848

Viviane Beineke é Professora do Departamento de Música e Coordenadora do Programa de Pós-Graduação em Música da UDESC. Bolsista de Produtividade pelo CNPq (Conselho Nacional de Desenvolvimento Científico e Tecnológico). Mestra e doutora em Música pela Universidade Federal do Rio Grande do Sul (UFRGS). Realizou Pós-Doutorado na LudwigMaximilians-Universität München (LMU), na Alemanha. É editora da Revista Música na Educação Básica, da Associação Brasileira de Educação Musical. Desenvolve pesquisas sobre criatividade e práticas musicais criativas, metodologias de ensino de música, produção de materiais didáticos e formação docente. https://orcid.org/0000-0003-2056-8149 